\title{
News media coverage of conflict and cooperation dynamics of water events in the Lancang-Mekong River basin
}

\author{
Jing Wei ${ }^{1}$, Yongping $\mathrm{Wei}^{2}$, Fuqiang Tian ${ }^{1}$, Natalie Nott $^{2}$, Claire de Wit ${ }^{2}$, Liying Guo ${ }^{1}$, and You Lu ${ }^{1}$ \\ ${ }^{1}$ Department of Hydraulic Engineering, State Key Laboratory of Hydroscience and Engineering, \\ Tsinghua University, Beijing 100084, China \\ ${ }^{2}$ School of Earth and Environmental Sciences, University of Queensland, St. Lucia, QLD 4072, Australia
}

Correspondence: Fuqiang Tian (tianfq@ mail.tsinghua.edu.cn)

Received: 29 July 2020 - Discussion started: 17 August 2020

Revised: 31 December 2020 - Accepted: 12 January 2021 - Published: 31 March 2021

\begin{abstract}
Riparian countries have their respective values and priorities for water management, and their values of shared water have fundamental impacts for their propensity to be involved in cooperative management and adhere to treaties/agreements. However, there is limited understanding of the changing values and interests of each riparian country. Taking the Lancang-Mekong River basin as a case study, this paper aims to analyse the evolution of water conflict and cooperation dynamics from the perspectives of multiple countries. Newspaper articles were used as the key data source as they provide insights into events reported on by the media that are representative of each country/sector they are published within. The results depict a trend of cooperative sentiments towards water events occurring within the region. The six riparian countries (China, Myanmar, Laos, Thailand, Cambodia, and Vietnam) had a greater average sentiment score (0.5) for cooperation than international countries (0.16) for the majority of the study period. The trend also shows that countries further downstream showed lower cooperative sentiments, except for Vietnam (China 0.86, Myanmar 0.58, Laos 0.46, Thailand 0.34, Cambodia 0.13, Vietnam 0.91 ). Dam infrastructure was often negatively reported (60\% of negatively reported articles), which is therefore a major contributor to conflict for the Lancang-Mekong River basin. Events that are positively reported are those that aid in connecting leaders and project developers between riparian countries including meetings, bilateral and multilateral cooperation, and development projects. These findings provide the basis for further revealing the mechanism of cooperation and conflicts as well as more proactively managing cooper-
\end{abstract}

ation and conflict in the Lancang-Mekong River basin and beyond.

\section{Introduction}

Globally there are 310 transboundary rivers that flow across more than $47 \%$ of the world's land surface (McCracken and Wolf, 2019), providing approximately $60 \%$ of the global river flow (Wolf et al., 2005). Transboundary rivers flow across political boundaries, which often results in very different views on how the transboundary water should be used and managed among its riparian countries (Sunchindah, 2013). Tensions and uncertainties often occur when sharing this consumable, indispensable resource and are further compounded by the dynamic interaction of hydrological, technical, and social systems (Zeitoun and Mirumachi, 2008). Transboundary rivers are therefore characterised by cooperation and conflict dynamics (Wolf et al., 1999; PetersenPerlman and Wolf, 2015; Yoffe et al., 2003; Zeitoun and Mirumachi, 2008).

Understanding transboundary waters through the lens of conflict and cooperation has been a dominant approach embraced by many scholars in different disciplines (Wolf et al., 2003; Yoffe et al., 2003; De Stefano et al., 2010; Zawahri, 2008; Gleick, 1998). As the fundamental advance to analyse the tendency for transboundary water conflict or cooperation, some inventories have been created to provide a global snapshot and recognise future tensions. Often cited is the Transboundary Freshwater Dispute Database (TFDD), developed by Oregon State University (Wolf, 1999), that compiled his- 
torical water incidents, both conflictive and cooperative, on a global scale from 1948 to 2008. Based on the data, Basins at Risk (BAR) project (Yoffe and Larson, 2001) categorised intensities of water incidents, varying between -7 and +7 , in order to understand possible social-political threats.

However, the current event-based approach is inadequate to recognise the nuanced nature of conflict and cooperation instances; i.e. there is a lack of understanding of individual riparian countries' attitude or values toward the shared river. Simply classifying water events into conflict or cooperation could mask various forms of underlying conflictive or cooperative responses elicited from each riparian country (Watson et al., 2009). Riparian countries have their respective values and priorities for water management (Wolf et al., 2005; Di Baldassarre et al., 2013), and their attitudes toward shared water often have fundamental impacts for their propensity to be involved in cooperative management and adhere to treaties/agreements. Understanding values in the context of transboundary rivers is therefore vital for developing effective management policies and strategies toward cooperation (Bennett and Dearden, 2014; Hartley, 2006; Larson et al., 2009; Turner et al., 2014).

Values, arising from the concept of culture, along with norms and beliefs, posit deeply held ideas that influence water management decisions and outcomes (Caldas et al., 2015; Roobavannan et al., 2018; Wei et al., 2017). Shaping the way people see, perceive, and interpret the outer environment (Caldas et al., 2015), a value is considered to be a mediating variable that connects humans with the natural environment. In the context of transboundary rivers, where multiple water users are interconnected (Petersen-Perlman et al., 2017), their different values towards their shared water are often manifested as conflictive or cooperative attitudes toward other competing water users. It could result in greater cooperation or conflict at a basin scale when further complicated by the interdependent web of hydrological, political, economic, technical, and social processes (Dinar, 2004; Di Baldassarre et al., 2019). Improving transboundary water management, therefore, firstly requires nuanced understanding of the changing values and interests of each riparian country; however, it remains under-researched.

Recently, conflict and cooperation dynamics in transboundary rivers have also been considered to be a sociohydrological phenomenon (Di Baldassarre et al., 2019) that emerges as a result of the long-term evolution of hydrological, political, economic, technical, and social processes present within the transboundary river system (Di Baldassarre et al., 2019). A socio-hydrological approach, which emphasises the feedback between human and water, is thus proposed to unravel how and why different actors have came into cooperation. However, challenges exist in how to measure values as the key social element in the socio-hydrological approach for developing the transboundary socio-hydrological models.
Therefore, this paper aims to provide a new perspective to understand conflict and cooperation dynamics by highlighting individual countries' attitudes towards their shared water. The Lancang-Mekong River basin is taken as a case study to investigate how the conflict and cooperation dynamics has changed over time and the main issues associated with the conflictive and cooperative sentiments. This paper can serve as a reference for water managers to collaboratively identify, manage, and overcome potential conflicts to achieve effective transboundary water management. It can also serve as a reference to measure the value in the socio-hydrological approach to contribute to understanding the mechanism that drives the conflict or cooperation choices in the long run.

\section{Case study area - Lancang-Mekong River basin}

The Lancang-Mekong River is one of the largest and longest river systems in South-East Asia. It flows from the Tibetan Plateau in China, down $4880 \mathrm{~km}$ through Myanmar, Lao PDR (Laos), Thailand, and Cambodia, and exiting into the South China Sea through Vietnam (MRC, 2019), as seen in Fig. 1. The river course that runs within China is named the Lancang River, whilst downstream it is referred to as the Mekong River. The Lancang-Mekong River is an essential water source that supports the livelihoods of some 65 million people from the six riparian countries by maintaining food security (Dugan et al., 2010).

The Lancang-Mekong River has experienced a lengthy record of conflictive and cooperative events; see Fig. 2. Significant movement towards cooperation over water resources between the riparian countries primarily began in the 1950s when the Mekong Committee was established, consisting of the lower Mekong countries, after the Geneva Convention granted independence to Laos, Cambodia, and Vietnam (Hirsch and Cheong, 1996). This committee ran from 1957 to 1978 despite disagreements among the riparian countries in how the decision-making processes were implemented (Bunny, 2014). In 1995, all members of the Mekong River Commission (hereafter, MRC) signed the "Agreement on the Cooperation for the Sustainable Development of the Mekong River Basin" (Hirsch and Cheong, 1996), with China and Myanmar presenting as dialogue partners of the MRC throughout discussions (Bunny, 2014). The beginning of the 21 st century has marked China's cooperative commitment for providing its water level and rainfall data for 5 months of the flood season during June-October, as well as entering cooperative regimes with the MRC (Dore, 2003). Meanwhile, the construction of large-scale dams upstream has received mounting criticism; i.e. the construction of the Xayaburi dam, as the first of the 11 proposed cascade dams on the Lower Mekong River, began in 2010 despite a lack of agreement between all four lower Mekong countries and failure of the regional consultation process. After that, several treaties and plans were signed, including the 


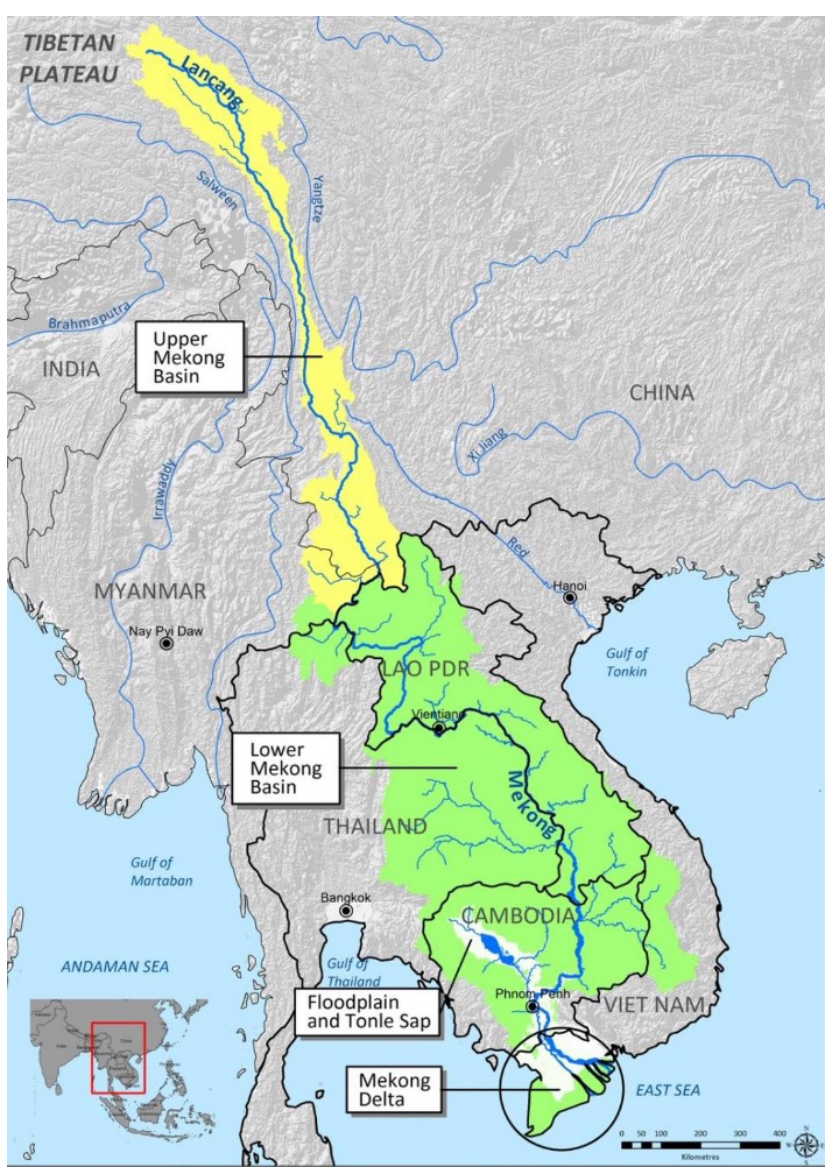

Figure 1. The location of the Lancang-Mekong River, the main river pathway, and its tributaries across the six riparian countries (MRC, 2019).

Lancang-Mekong Cooperation Mechanism in 2015, marking a significant step towards cooperation.

One of the most prominent reasons behind the tension between the riparian countries is their competing desires for the use of the water. China in particular has an interest in hydropower projects to generate electricity and also in clearing and expanding waterways to improve navigation for greater trade (Bunny, 2014). Myanmar, with access to a small part of the Lancang-Mekong River through the share of a border with Laos, has not projected a preferred use of the water vocally but is generally cooperative with China (Bunny, 2014). Laos, similarly to China, also has a great interest in hydropower developments (Dugan et al., 2010). Thailand primarily diverts water from the main Lancang-Mekong tributaries into its north-eastern areas for irrigation (Nesbitt, 2005). Cambodia has a particular interest in preserving water quantity and quality for their fishery sector to ensure aquatic species abundance (Bunny, 2014). As a result, Cambodia demands that fewer large structures are constructed along the main river, such as dams and irrigation systems that may affect the sediment flow and water quantity downstream
(Bunny, 2014). Similar to Cambodia, Vietnam has the same interests in utilising the water for agriculture and aquaculture and generally contests upstream dams that will have possible negative effects on its water quantity and quality (Nesbitt, 2005).

\section{Methods}

Newspaper articles provide insights into events reported on by the media that are representative of the individual country/sector they are published within (Cooper, 2005). Through their noted "agenda-setting" capability, newspapers reflect what is important to the public as well as shaping the public perception of an issue (Bengston et al., 1999; Hurlimann and Dolnicar, 2012; Neuendorf, 2017). Newspapers have increasingly been recognised as a valid proxy to track societal values or public opinion on water issues (Quesnel and Ajami, 2017). Therefore, utilising newspaper articles as a key data source allows for the analysis of the perceptions of different countries pertaining to water events over time.

This study takes newspapers as data sources to uncover the conflictive and cooperative sentiments and associated topics. A step-by-step illustration of how the data are retrieved and analysed is given in Fig. 3. First of all, newspaper articles were retrieved from a database using predefined keywords, which resulted in a total of 12314 articles. All of these articles were then manually read by authors to remove irrelevant and duplicates articles based on predetermined criteria, which left 3877 articles for final analysis. These articles were classified based on their origin of publication, and the conflictive and cooperative sentiments expressed from these articles were then determined using sentiment analysis, and the main topics associated with conflict and cooperation were analysed using topic analysis. More detailed step-by-step information is illustrated in each section below.

\subsection{Data retrieval}

The LexisNexis database was selected to extract newspaper information. It is home to more than 6000 news publications from around the world and is among the most commonly used news sources in the field of social sciences (Weaver and Bimber, 2008; Racine et al., 2010). The searching scope includes both major regional and international English newspapers. Although English is not frequently used in most riparian countries within the Lancang-Mekong Basin, English newspapers are accessible and regularly reach an international audience and are therefore considered a reference to the government's foreign policy (Curtin, 2012). News articles in these newspapers reflect national interests and political responses that riparian countries want to deliver to the international public.

The search terms are one of the key determinants of the validity of the data to be collected. The search terms used 


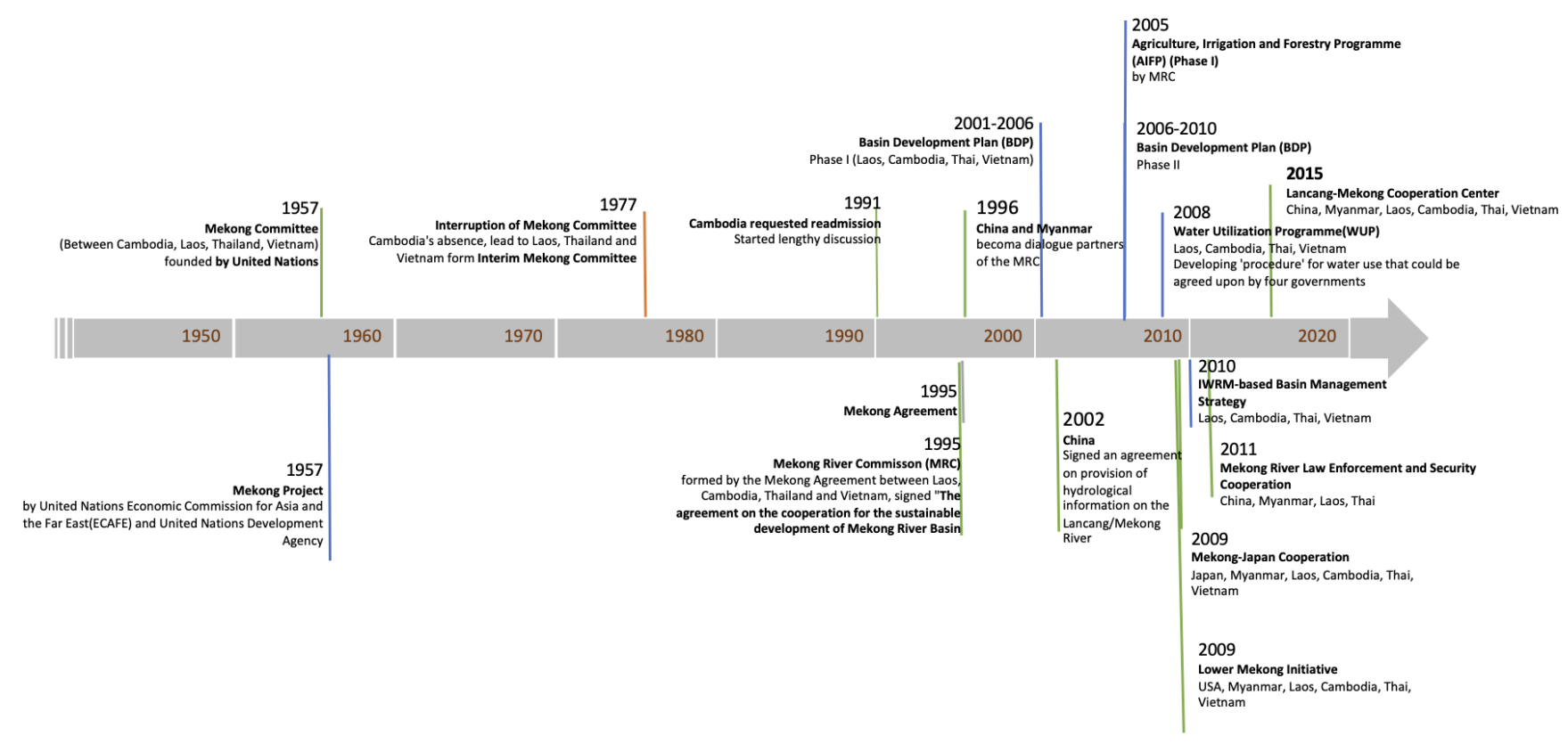

Figure 2. History of major events within the Lancang-Mekong River basin.

in this study, as seen in Table 1, were adopted from Yoffe and Larson (2001) and refined to reflect the results of water events along the Lancang-Mekong River. Specifically, the search terms require that articles to be included must discuss "Mekong" River basin in one of the topics indicated in the table (e.g. dam, irrigation, pollution). These articles need to discuss the conflictive or cooperative aspects of the events involving at least one of the riparian countries. The above categories can narrow down the search to the desired scope, with the list of unwanted words to further screen out irrelevant topics. It should be noted that the search did not limit the time frame but aim to include all that is relevant in discussing conflict and cooperation water events.

\subsection{Data cleaning}

Initially, the search generated a total of 12316 results. All articles were then manually read and examined for their relevancy using the criteria in Table 2 to be reflective of the perspectives of water events along the Lancang-Mekong River. Those articles not relevant were removed from the analysis alongside any duplicate articles and those with missing necessary information, including article body and date published. The final number of articles utilised for the analysis was 3877 .

\subsection{Sentiment analysis and topic analysis}

Generally, there are two types of coding methods available when examining the news content, manual coding and computer-assisted coding. While manual coding could uncover latent content to a larger extent (Wei et al., 2015; Wei et al., 2017), it is more time-consuming and less efficient when examining large datasets. Sentiment analysis, a widely used computer-assisted analysis, was utilised in determining the cooperative or conflictive perspectives towards water events. It is the process in which thoughts, attitudes, and perceptions expressed in a text are identified and classified in a computational way, particularly in order to determine authors' viewpoints and position towards certain issues (positive, negative, or neutral) (Danneman and Heimann, 2014). This process was conducted through the interface of $\mathrm{R}$, which involved inputting textual data into the program, tokenising the sentences to differentiate each word from one another, and then attaching the tokenised text to a sentiment lexicon to identify the overall sentiment (Danneman and Heimann, 2014). As there is no "conflict and cooperation" lexicon for transboundary rivers available, a general sentiment lexicon, AFINN, was utilised in this analysis. AFINN contains a total of 2477 attached word sentiments, which produce a positive and negative value on a scale from -5 to +5 (Nielsen, 2011). In order to represent the conflictive and cooperative sentiments, the searching scope has limited the articles' content to instances of cooperation or conflict that occur within the Lancang-Mekong River basin, involving one or more riparian countries. Therefore, the calculated sentiment scores based on AFINN scores ranging from -5 to +5 were considered, in order to be able to reflect the intensity of conflict and cooperation accordingly.

To reflect topics associated with conflict or cooperation in water events, a topic analysis approach, the structural topic model (STM) (Roberts et al., 2014), was utilised. The structural topic model (STM) allows frequent words to be 

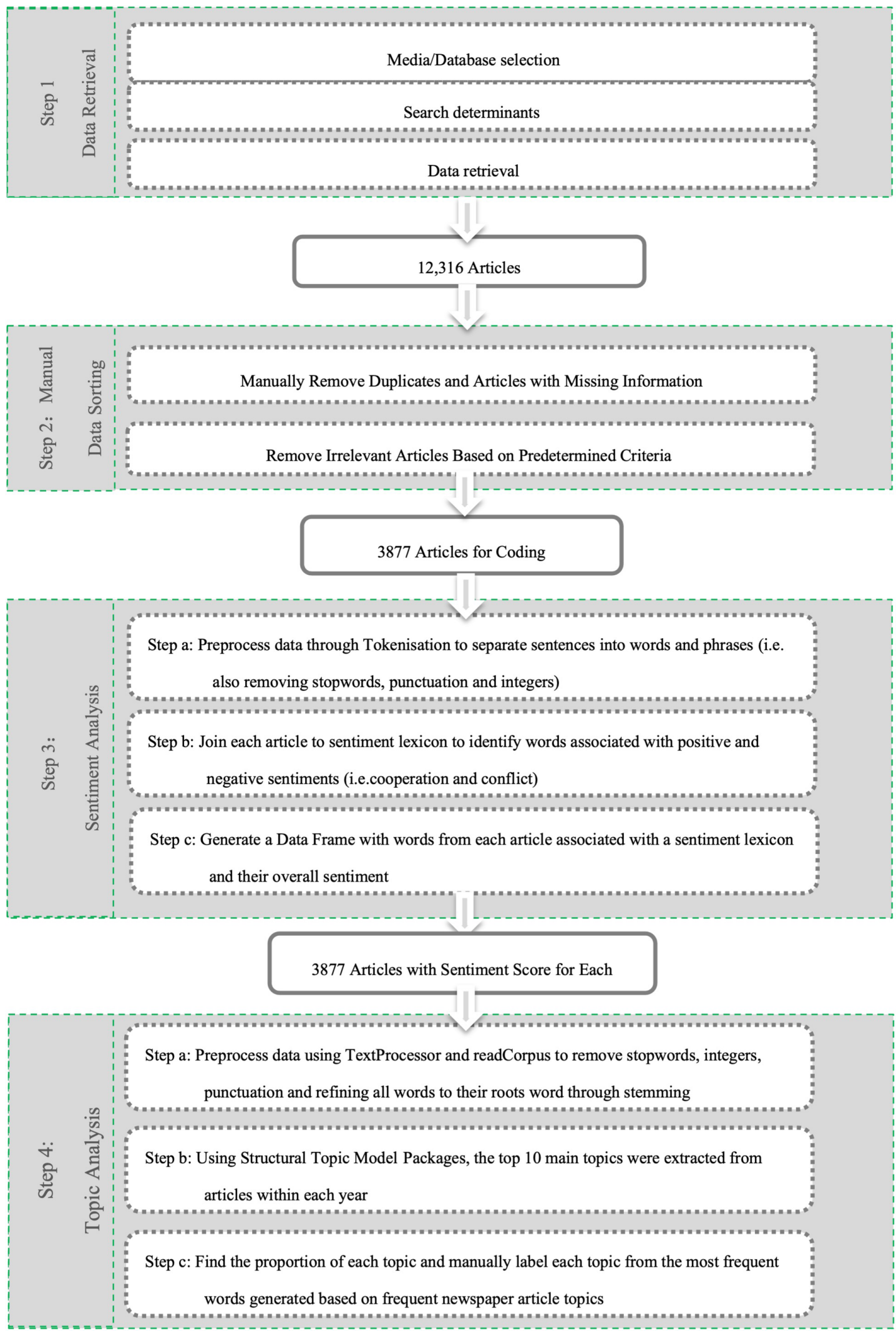

Figure 3. Outline of the data retrieval process and coding for sentiment analysis and the structural topic model. 
Table 1. Search terms established to generate results. The asterisk is used to represent the root word; i.e. water* means words containing the root word "water" are included.

\begin{tabular}{ll}
\hline LexisNexis requirements & Keyword search \\
\hline Must include the following words: & Mekong \\
\hline $\begin{array}{l}\text { Includes at least one of the following words re- } \\
\text { lated to water: }\end{array}$ & $\begin{array}{l}\text { water* or river* or lake* or dam* or stream* } \\
\text { or tributar* or diversion* or irrigati* or polluti* } \\
\text { or "water quality" or flood* or drought* or } \\
\text { channel* }\end{array}$ \\
\hline $\begin{array}{ll}\text { Includes at least one of the following words re- } \\
\text { lated to conflict and cooperation: }\end{array}$ & $\begin{array}{l}\text { treat* or agree* or negotiat* or resolution* or } \\
\text { commission* or secretariat* or "joint manage- } \\
\text { ment" or "basin management" or "peace ac- } \\
\text { cord" or settle* or cooperat* or collaborat* or } \\
\text { dispute* or conflict* or disagree* or sanction* } \\
\text { or war* or troop* or "letter of protest" or hostil* } \\
\text { or "shots fired" or boycott* or protest* }\end{array}$ \\
\hline $\begin{array}{l}\text { Includes at least one of the following words re- } \\
\text { lated to countries involved: }\end{array}$ & $\begin{array}{l}\text { Thai* or Cambodia* or China or Chinese or } \\
\text { Lao* or Myanmar* or Burm* or "viet nam" or } \\
\text { Vietn* }\end{array}$ \\
\hline Does not include any of the following words: & $\begin{array}{l}\text { sea, ocean, navigation, nuclear, "water cannon", } \\
\text { "light water reactor", "mineral water", "hold } \\
\text { water", "cold water", "hot water", "water can- } \\
\text { ister", "water tight", "water down", "flood of } \\
\text { refugees", oil, drugs }\end{array}$ \\
\hline
\end{tabular}

Table 2. Criteria for inclusion and exclusion of news articles.

\begin{aligned} & \hline Criteria for including data - Irrigation using the Lancang-Mekong river as a source \\ & - Conflict over water resources, e.g. proposed development \\ & - Cooperation over water resources, e.g. bilateral/multilateral agreements, MRC, ASEAN \\ & - Species affected by development projects, e.g. pollution, water quantity and quality \\ &- Salt intrusion due to decreased water quantity and flow from upstream, e.g. dams/diversions \\ & - Livelihoods affected by use of water resources, e.g. dams, diversions, dam failures, contamination \\ & of water \\ & - Flooding or droughts as a result of water release or containment in dams \\ & - Infrastructure development that can affect water resources/species, e.g. proposed bridge develop- \\ & ment, dams, diversions \\ &- Tourism not related to the use of water resources by riparian countries, e.g. cruises, blogs, personal \\ & recounts \\ &- War, e.g. history of Vietnam War, awarding of medals \\ & - Economic development not related to water resources in Lancang-Mekong River \\ &- Bridges across the Lancang-Mekong River and not referring to effects on water resources \\ &- Tariffs and trade agreements that have no association with water resources \\ &- Border conflicts not pertaining to water resources, e.g. security, border control, land ownership \\ & disputes \\ & \hline\end{aligned}

extracted from text, identifying commonalities between the words, phrases, and groups of words to generate a topical prevalence and topic content factor (Roberts et al., 2014). This tool is particularly useful when managing big data sources as the process to identify key topics manually is inefficient and time-consuming, whereas STM has the ability to identify topics automatically. The STM was processed by using the STM package in R (Roberts et al., 2014). The number of topics selected was 10 , which was decided through an analysis of the topics produced until clear, relevant topics emerged as a result. For example, at five topics, all topics were pertaining to water, resources, and the six riparian countries; however, at 10 topics, there were more clear topics emerging, such as dam infrastructure, agriculture, and fish- 


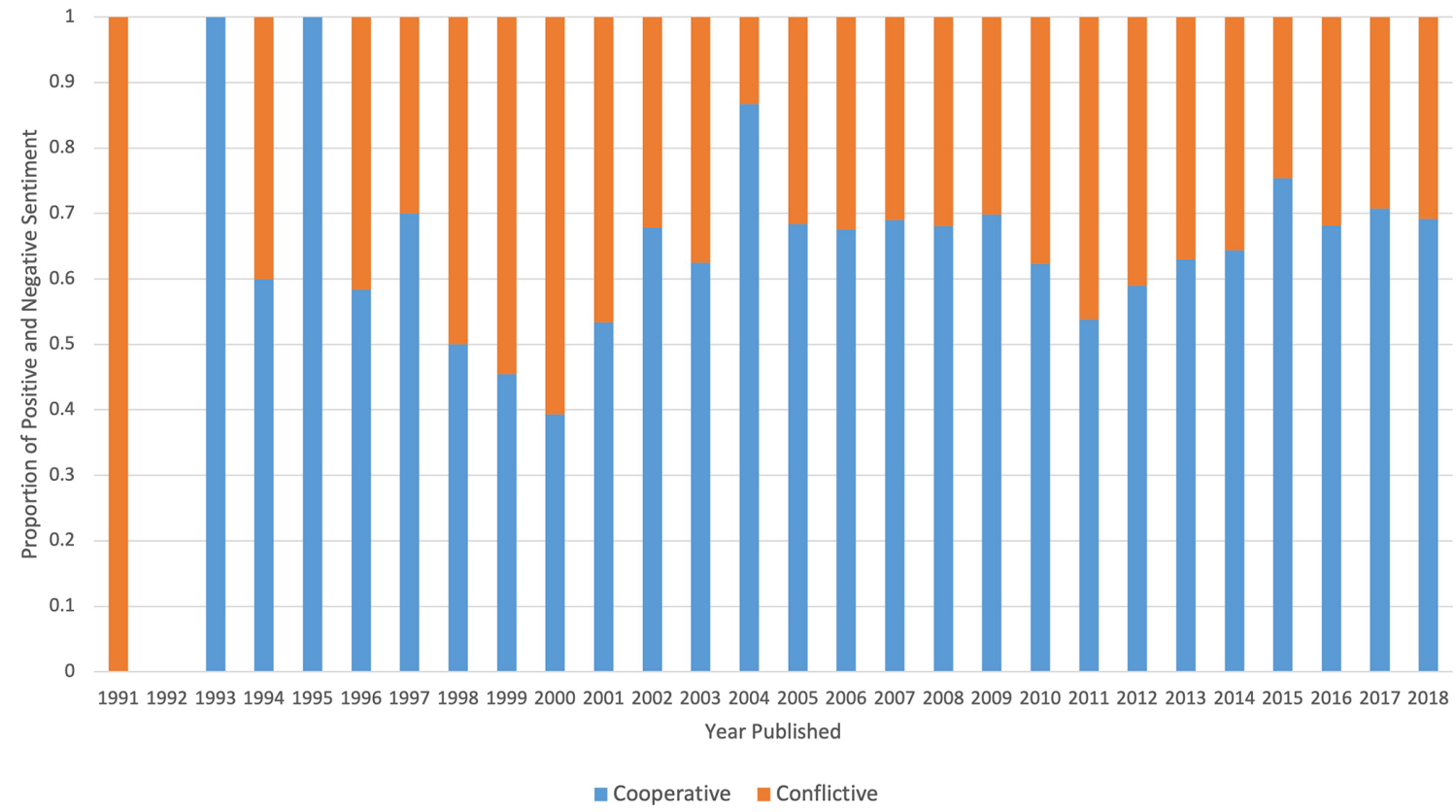

Figure 4. Proportion of cooperation and conflict articles published pertaining to water events along the Lancang-Mekong River basin.

eries. The topics were then manually labelled based on the most frequent words found within each topic, as the statistical software cannot extrapolate the overall topic from most frequent words. Topic labelling was based on previous literature reviews and the main water-related topics outlined in the study of Wei et. al. (2015).

\section{Results}

\subsection{Overall news coverage of conflict and cooperation water events in the Lancang-Mekong River basin}

Overall, there was an observed increase in both the number of conflictive and cooperative articles published over time. There has consistently been a greater number of articles with cooperative sentiment than conflictive sentiments since 2002 (Fig. 4). This ratio of cooperative to conflictive articles published has remained relatively stable since 2000 , with the majority of all years having $60 \%$ to $70 \%$ of all articles being cooperative. There are also multiple peaks and troughs in terms of the proportion of cooperative and conflictive reported articles shown in Fig. 4; peaks were reached in year 2004 and 2015, and troughs were found in year 2011.

\subsection{Topics associated with conflict and cooperation sentiments}

To understand the most relevant topics associated with conflict and cooperation sentiments, topic analysis was conducted, with 10 topics identified. It was found that nearly one-third of all articles were pertaining to dam infrastructure, implying that this is a significant topic that countries have a vested interest in (Fig. 5a). Following this, there is a large proportion of topics that are associated with the reporting of relationships between countries or their cooperation, i.e. bilateral relations, multilateral relations, joint management, and meetings.

Figure $5 \mathrm{~b}$ also depicts the proportion of topics that are frequently associated with conflictive sentiment. Dam infrastructure and hydropower, which operate hand in hand, were negatively reported by the media, accounting for $60 \%$ of the total negative topics, whilst another $10 \%$ of all negative articles had a focus on meetings, bilateral relations, flooding, and fishing/environment.

Upon investigation into the specific concerns about dam infrastructure, major concerns over the construction of dams are associated with water quantity and the effects this has on sediment flux, water discharge, fisheries, and water access for irrigation and agriculture. It is also found that not just the construction and operation of the dam received a significant amount of negative media attention, but also the proposal and planning process.

When analysing the major topics that prompt a greater cooperative sentiment towards water events in the media, it is clear that there are five main topics that are focused on: development, meetings, hydropower, bilateral cooperation, and multilateral cooperation (Fig. 5c). Development, meetings, and hydropower are key topics, accounting for $22.22 \%$ of topic relevance to articles. 


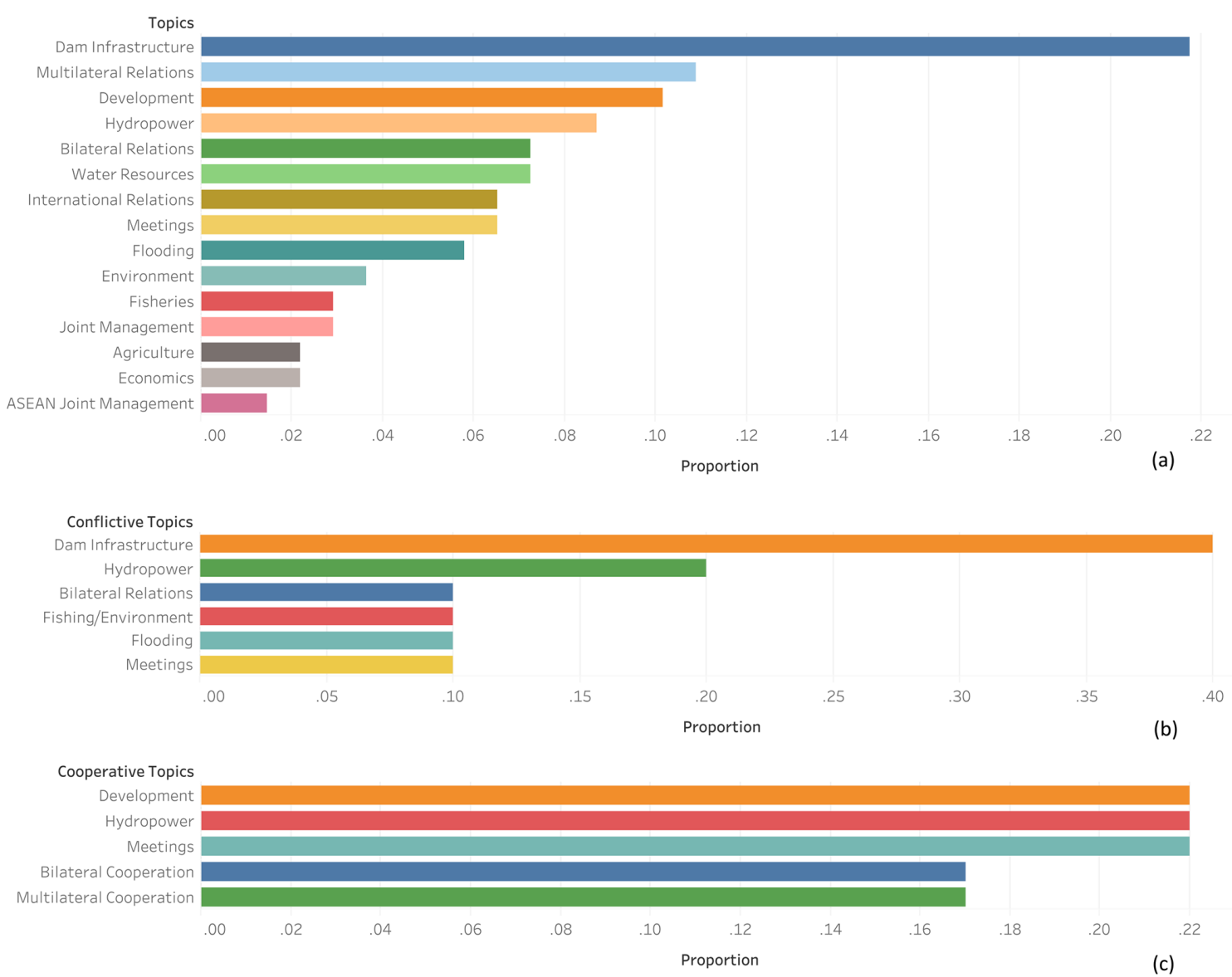

Figure 5. The proportion of all topics identified as key topics in newspapers from 1991 to 2018 (a). The proportion of topics identified with an overall conflictive sentiment (b). The proportion of topics identified with an overall cooperative sentiment (c).

\subsection{Dynamics of conflict and cooperation sentiments as perceived within and beyond the basin}

Conflictive and cooperative sentiment as reflected within and beyond the basin countries was calculated to reveal detailed insights into the evolving perspectives, as seen in Fig. 6a. It was observed that from 1991 to 2018 there is an apparent trend in increasing cooperative sentiment scores for both international (beyond the basin) and regional (within the basin) publications (Fig. 6a). The six riparian countries had a greater average sentiment for cooperation than international countries for the majority of the timescale, showing that the region perceived transboundary water management in the Lancang-Mekong River basin more positively than global audiences. There has also been a decreased difference between international and regional sentiments over time, with a similar sentiment score between 2008 and 2018 approximately. This figure also highlights some of the key players in transboundary river basin management for the LancangMekong region, such as Australia and the United States of America (Fig. 6b). Both Australia and the United States of America are development partners of the region and thus pos- itively involved in the water management. Philippines is one of the major publication places for the Asian Development Bank (ADB), which is a key player for funding and international aid and thus has also been frequently mentioned in the publications.

\subsection{Dynamics of conflict and cooperation sentiments as perceived from each riparian country}

Most importantly, Fig. 7 shows the average sentiment scores for each of the riparian countries from 1991 until 2018. The results showed that all riparian countries demonstrated mostly cooperative sentiment; overall average sentiment scores in order of lowest to highest are Cambodia (0.13), Thailand (0.34), Laos (0.46), Myanmar (0.58), China (0.86), and Vietnam (0.91). Upstream riparian countries, such as China, Laos, and Myanmar, exhibit more positive sentiments compared to the downstream countries, Cambodia and Thailand (Fig. 7). One major outlier is Vietnam, the most downstream country, which exhibits the highest sentiment value among all riparian countries. With the exception of Vietnam's sentiment score, the trend shows that countries further 
Average Score of International and Regional Articles Over Time

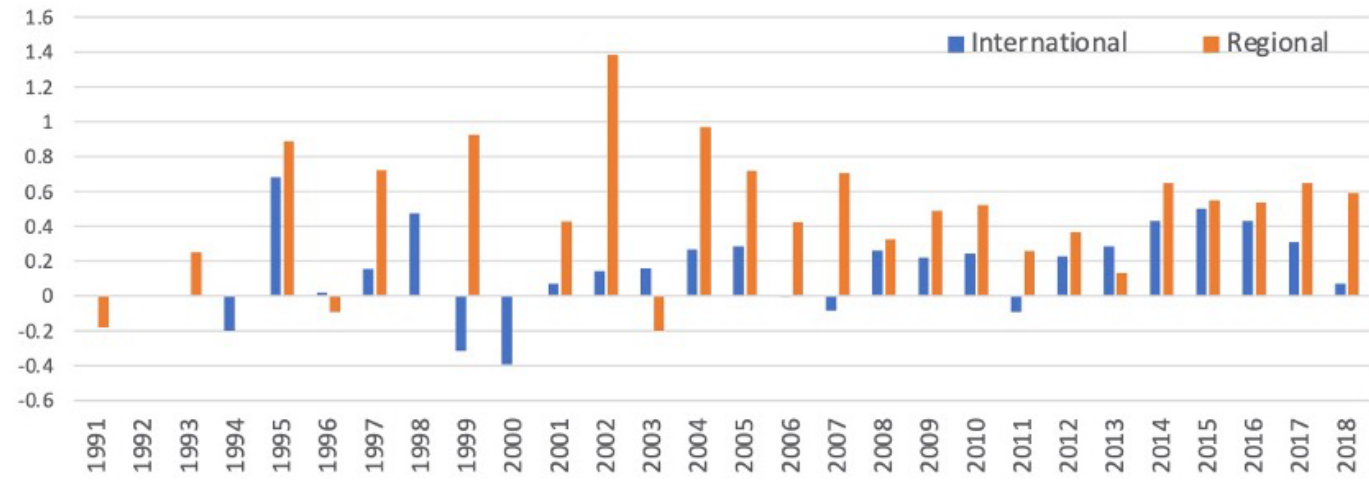

(a)

\section{Conflict and Cooperation Sentiments Perceived within and beyond the Basin}

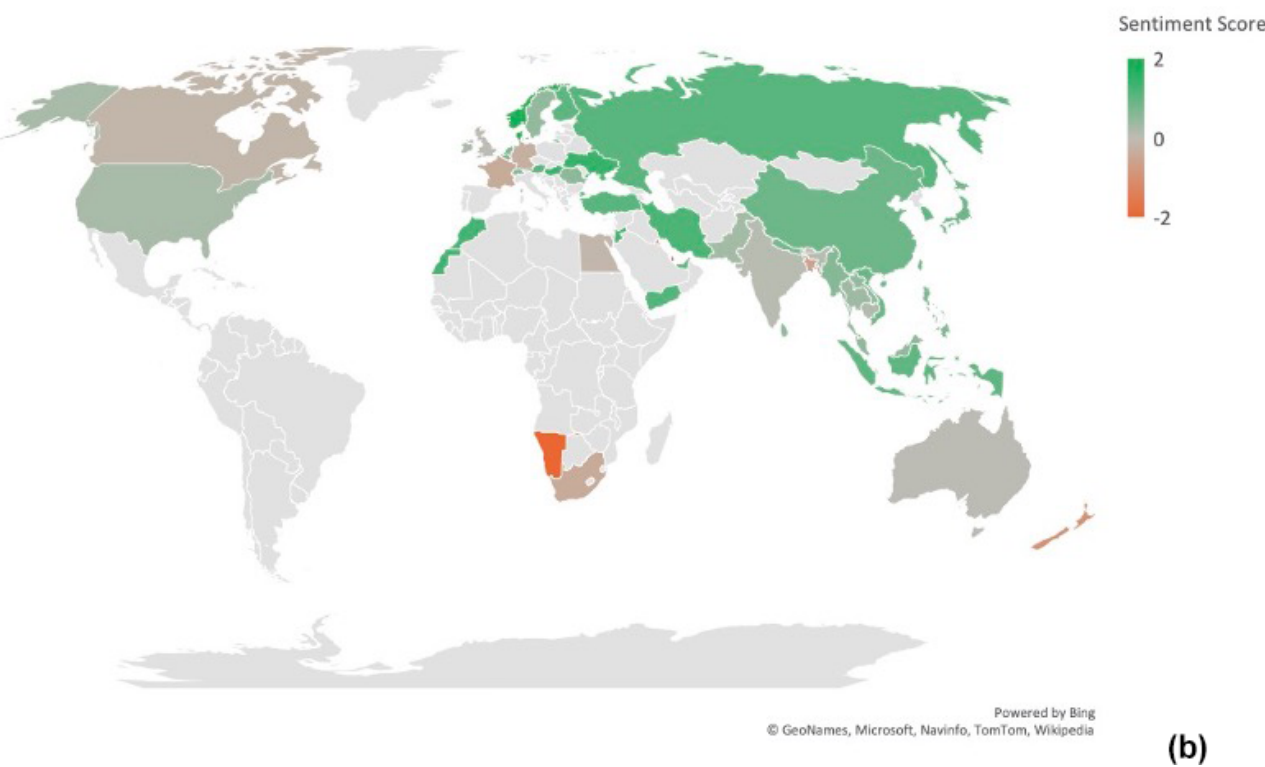

Figure 6. The average sentiment score of regional and international newspapers from 1991 to 2018 (a). Conflict and cooperation sentiments perceived within and beyond the basin (b).

downstream show more conflictive sentiments. China has also consistently expressed very positive sentiments (Fig. 8). Upon inspection into the articles from China, predominantly published by Xinhua News, the Lancang-Mekong Cooperation (LMC) is a common occurrence in the text that contributes to China's positive outlook on transboundary river basin management in the region. Thailand presents similar results, except for one year, 2011, which shows a negative average sentiment score. Laos' average sentiment scores between 2007 and 2018 were very variable and do not seem to follow any certain trend. Cambodia showed predominantly negative average sentiment scores as fishing issues were of concern, cited in newspapers throughout the study period. Myanmar has minimal data, with only 32 articles found in total, and only one year, 2014, showed a negative average sentiment score.

\section{Discussions and conclusions}

It is important to understand the change of sentiments toward shared transboundary water resources to be able to understand countries' cooperative or non-cooperative behaviour and the factors that encourage and discourage changes toward cooperation or conflict. This paper develops a new perspective to understand the evolution of conflict and cooperation dynamics, with an in-depth analysis of multiple countries. Key findings are summarised and discussed below. 


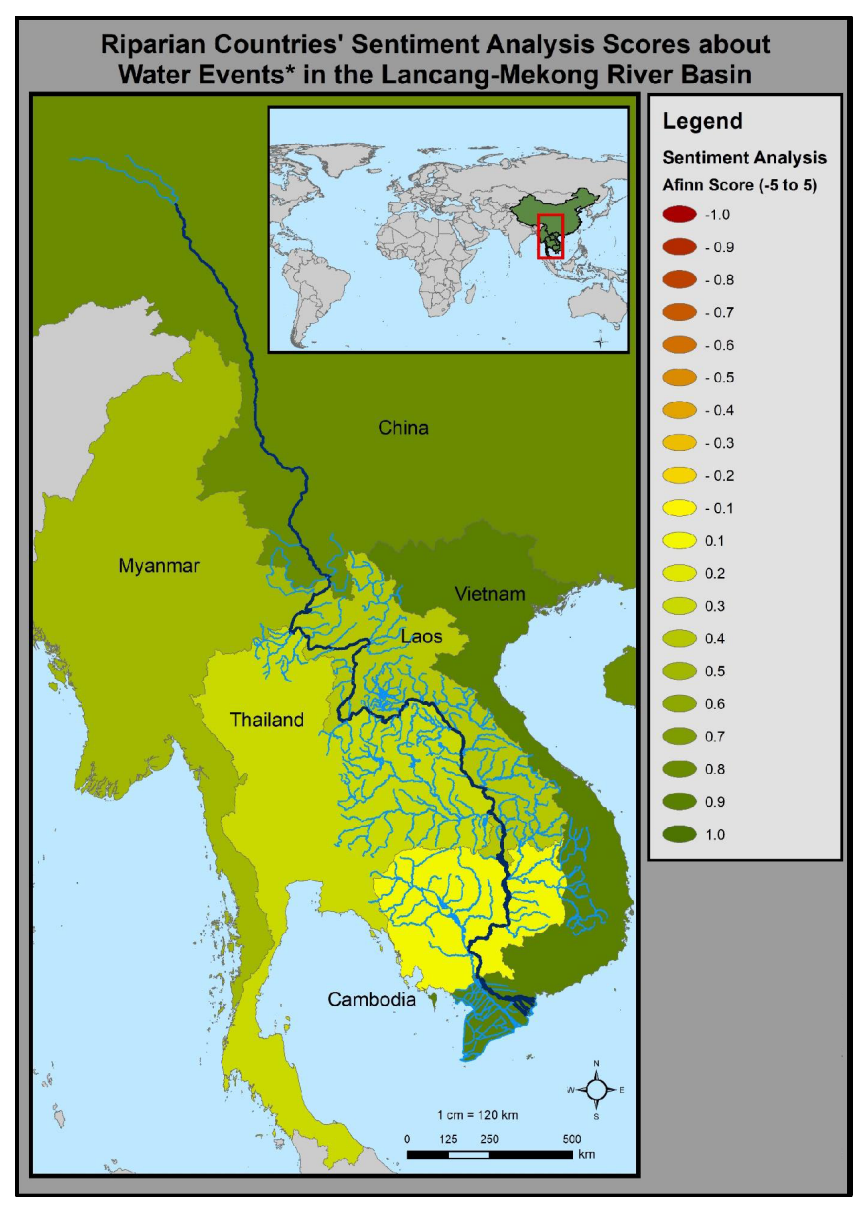

Figure 7. Average conflict and cooperation sentiment score of each riparian country between 1991 and 2018 .

The overall sentiment analysis depicts a current trend of cooperative sentiments towards water events occurring within the region. This is in contrast with previous studies, in which the dominant trend in media coverage analysis was a decrease of cooperative events from 1948 to 2008 (De Stefano et al., 2010). This research was able to bridge the gap in the literature and depict recent trends that the proportion of cooperative to conflictive articles has not continued to drop but has started to rise in favour of cooperative events. This can be attributed to the fact that dam construction and infrastructure development are the key controversial issues. Our topic analysis (Fig. 5b) shows that the majority of negative sentiments were associated with these topics, which has also been revealed in worldwide transboundary rivers (De Stefano et al., 2010). Therefore the absence and presence of dam-related topics mark the ups and downs of the cooperative sentiment trend. As found in a previous study (De Stefano et al., 2010), dam proposals and construction topics were absent during 1948-1999, and at the same time cooperative events account for $94 \%$ of the total events. Starting from the late 1990s, dam proposals and construction started to be discussed, which attracted concern associated with infrastructure development along the river and resulted in the slight downturn of the cooperation trend, as seen in Fig. 4. After 2000, Mekong River attracted attention from the international community for its management and development, financial and infrastructure aid started to flow in to assist cooperation within the basin, and the cooperation trend experienced a steady increase. In 2011, a slight decrease of cooperation was occurred due to the complaints received about the Laos Xayaburi dam project. With the completion of some major hydropower projects, the cooperation trend was further enhanced after the new cooperation mechanism was proposed and implemented involving all basin countries from the 2010s onwards.

It was also found that the greatest events that are positively reported on by the media are those that aid in connecting leaders and project developers between riparian countries, including meetings, bilateral and multilateral cooperation, and development projects. Development is also generally viewed positively in the media due to the potential for desired growth and is promoted by many international NGOs, including the ADB. In fact, the ADB aided in the establishment of the Greater Mekong Subregion Economic Cooperation in 1992 to focus on nine priority areas of economic growth along the Lancang-Mekong: transport, telecommunications, energy, tourism, human resources development, environment, agriculture, trade, and investment (Krongkaew, 2004). Thus, development is considered a crucial topic and action in providing greater cooperation and collaboration between riparian countries. By allowing this continual interaction and joint projects that facilitate riparian countries in considering all interests and impacts on a larger, transboundary river scale, there is great potential for future cooperation to solve the current issues within the Lancang-Mekong Basin.

This study also differentiated between international countries and regional countries in how each topic was perceived by the media. It was found that basin countries on average have a higher cooperative sentiment score than international countries in each year from 1991 to 2018. This is likely associated with the topics that are considered newsworthy to be published in a regional area, pertaining to another country. Generally speaking, when countries report on events not occurring within their close proximity and in different countries, they do so to focus on the major and complex issues and relationships that occur across the globe (Lewis, 2010). Hence, foreign news often focuses on significant instances of either great cooperative events such as international freshwater treaties and major strategic alliances or conflictive events, ranging from mild complaints to extensive war and hostile interactions of both a physical and verbal nature (De Stefano et al., 2010). This kind of asymmetric reporting on cooperative (positive) and conflictive (negative) water events can explain the lower sentiment score from international countries to a large extent. 


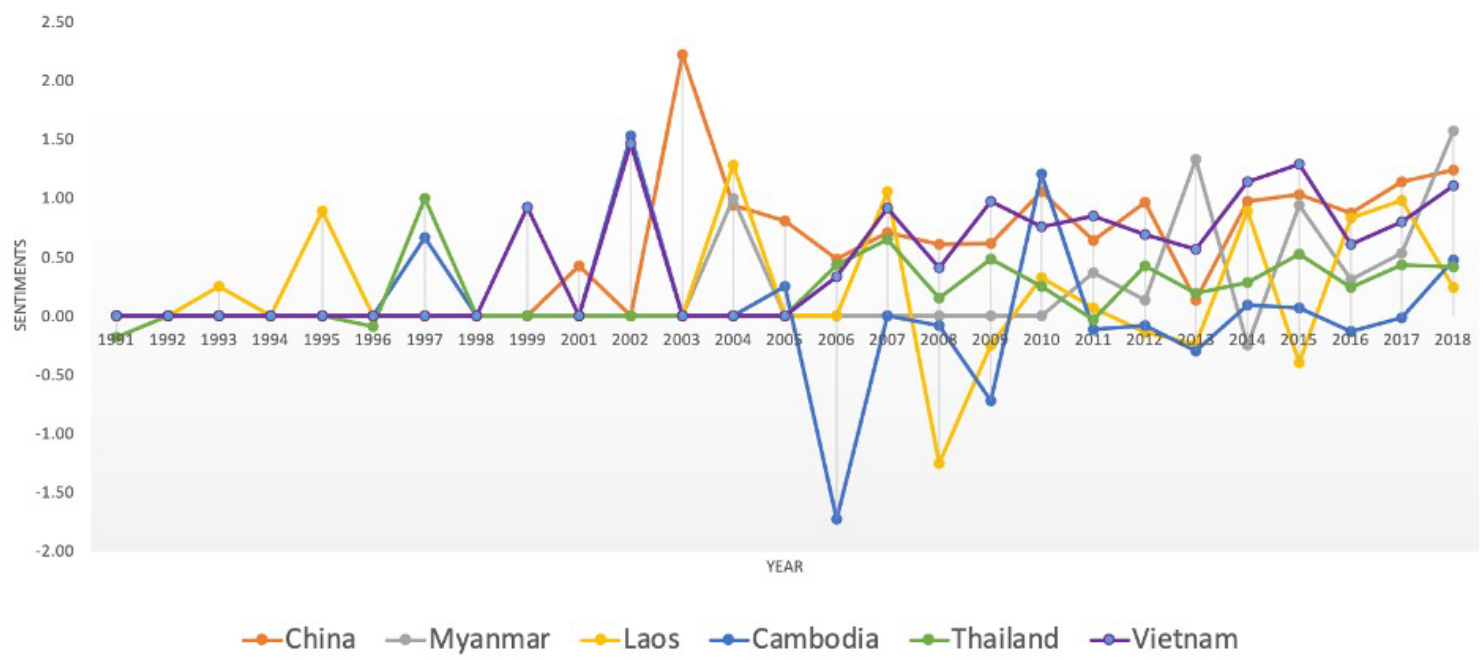

Figure 8. Conflict and cooperative sentiment scores of the riparian countries (Cambodia, China, Laos, Myanmar, Thailand, and Vietnam) from 1991 until 2018.

With the exception of Vietnam's sentiment score, the trend shows that countries further downstream showed lower positive sentiments. It was predicted that Vietnam and Cambodia would express negative sentiments; however, these expectations were not met in the study. The reason behind this pattern is that the true perspectives of some riparian countries including Vietnam and Cambodia could not be analysed as not many regional newspapers from those countries were accessible through LexisNexis, and as a result, this hinders the conclusions made. This is also one of the major limitations of this study that only English newspapers published in regional and international countries were included for analysis. For future research, it is imperative that a greater variety of newspaper sources covering local languages are utilised through using multiple newspaper databases in order to gain a representative analysis of the perspectives of all riparian countries.

The future of the Lancang-Mekong is reliant on the riparian countries to collaboratively manage these resources. If the cooperative water events continue to increase and the issues associated with negative events can be collaboratively identified, managed, and overcome, there is great potential for the region to achieve effective transboundary water management. As Kofi Annan, Secretary-General of the United Nations, argued in 2002, "The water problems of our world need not be only a cause of tension; they can also be a catalyst for cooperation. ... If we work together, a secure and sustainable water future can be ours." (Wolf, 2007).

Code and data availability. The data and code used in this study are publicly available at https://doi.org/10.5281/zenodo.4615696 (Wei et al., 2021a) (newspaper data with sentiment score) and https://doi.org/10.5281/zenodo.4486360 (Wei et al., 2021b) (sentiment analysis and topic analysis code).
Author contributions. JW, YW, and FT designed the research framework. JW, NN, and CdW collected data and conducted manual data sorting and data analysis. LG and YL revised the code for data analysis. JW, YW, and FT prepared the manuscript with contributions from all co-authors.

Competing interests. The authors declare that they have no conflict of interest.

Special issue statement. This article is part of the special issue "Socio-hydrology and transboundary rivers". It is not associated with a conference.

Acknowledgements. We would like to acknowledge the $\mathrm{Na}$ tional Natural Science Foundation of China (NSFC; grant no. 51961125204) and the National Key Research and Development Programme of China (grant no. 2016YFA0601603) for the funding and support of this research.

Financial support. This research has been supported by the National Natural Science Foundation of China (grant no. 51961125204) and the National Key Research and Development Programme of China (grant no. 2016YFA0601603).

Review statement. This paper was edited by Murugesu Sivapalan and reviewed by Tim van Emmerik and one anonymous referee. 


\section{References}

Bengston, D. N., Fan, D. P., and Celarier, D. N.: A new approach to monitoring the social environment for natural resource management and policy: The case of US national forest benefits and values, J. Environ. Manage., 56, 181-193, 1999.

Bennett, N. J. and Dearden, P.: Why local people do not support conservation: Community perceptions of marine protected area livelihood impacts, governance and management in Thailand, Mar. Policy, 44, 107-116, 2014.

Bunny, Y.: International Mekong River Basin: Events, Conflicts or Cooperation, and Policy Implications, MS Thesis, Oregon State University, Oregon, 65 pp., 2014.

Caldas, M. M., Sanderson, M. R., Mather, M., Daniels, M. D., Bergtold, J. S., Aistrup, J., Stamm, J. L. H., Haukos, D., DouglasMankin, K., and Sheshukov, A. Y.: Opinion: Endogenizing culture in sustainability science research and policy, P. Natl. Acad. Sci. USA, 112, 8157-8159, 2015.

Cooper, S. D.: Bringing Some Clarity to the Media Bias Debate, Rev. Commun., 5, 81-84, 2005.

Curtin, M.: Chinese media and globalization, Chin. J. Commun., 5, $1-9,2012$.

Danneman, N. and Heimann, R.: Social media mining with R, Packt Publishing, Birmingham, UK, 2014.

De Stefano, L., Edwards, L., de Silva, A., and Wolf, L.: Tracking cooperation and conflict in international basins: historic and recent trends, Water Policy, 12, 871-884, https://doi.org/10.2166/wp.2010.137, 2010.

Di Baldassarre, G., Viglione, A., Carr, G., Kuil, L., Salinas, J. L., and Blöschl, G.: Socio-hydrology: conceptualising humanflood interactions, Hydrol. Earth Syst. Sci., 17, 3295-3303, https://doi.org/10.5194/hess-17-3295-2013, 2013.

Di Baldassarre, G., Sivapalan, M., Rusca, M., Cudennec, C., Garcia, M., Kreibich, H., Konar, M., Mondino, E., Mård, J., and Pande, S.: Sociohydrology: Scientific challenges in addressing the sustainable development goals, Water Resour. Res., 55, 6327-6355, 2019.

Dinar, A.: Exploring Transboundary Water Conflict and Cooperation, Water Resour. Res., 40, W05S01, https://doi.org/10.1029/2003wr002598, 2004.

Dore, J.: The governance of increasing Mekong regionalism, Politics of the Commons: Articulating Development and Strengthening Local Practices, Chiang Mai, Thailand, 2003.

Dugan, P. J., Barlow, C., Agostinho, A. A., Baran, E., Cada, G. F., Chen, D., Cowx, I. G., Ferguson, J. W., Jutagate, T., and MallenCooper, M.: Fish migration, dams, and loss of ecosystem services in the Mekong basin, Ambio, 39, 344-348, 2010.

Gleick, P. H.: The human right to water, Water policy, 1, 487-503, 1998.

Hartley, T. W.: Public perception and participation in water reuse, Desalination, 187, 115-126, 2006.

Hirsch, P. and Cheong, G.: Natural Resource Management in the Mekong River Basin: Perspectives for Australian Development Cooperation, A Final Report to AusAID, University of Sydney, Sydney, Australia, available at: http://sydney.edu (last access: 30 June 2020), 1996.

Hurlimann, A. and Dolnicar, S.: Newspaper coverage of water issues in Australia, Water Res., 46, 6497-6507, https://doi.org/10.1016/j.watres.2012.09.028, 2012.
Krongkaew, M.: The development of the Greater Mekong Subregion (GMS): real promise or false hope?, J. Asian Economics, 15, 977-998, 2004.

Larson, K. L., White, D. D., Gober, P., Harlan, S., and Wutich, A.: Divergent perspectives on water resource sustainability in a public-policy-science context, Environ. Sci. Policy, 12, 10121023, 2009.

Lewis, D.: Foreign correspondents in a modern world: The past, present and possible future of global journalism, Elon Journal of Undergraduate Research in Communications, 1, 119-127, 2010.

McCracken, M. and Wolf, A. T.: Updating the Register of International River Basins of the world, Int. J. Water Resour. Dev., 35, 732-782, https://doi.org/10.1080/07900627.2019.1572497, 2019.

MRC: Summary, State of the Basin Report 2018, The Mekong River Commission, VIentiane, Lao PDR, 226, 2019.

Nesbitt, H.: Water used for agriculture in the Lower Mekong Basin, MRC Technical Paper, 11, 1683-1489, 2005.

Neuendorf, K. A.: The content analysis guidebook, second edition, Cleveland State University, Cleveland, USA, 2017.

Nielsen, F. Å.: A new ANEW: Evaluation of a word list for sentiment analysis in microblogs, arXiv [preprint], (last access: 10 May 2020), 2011.

Petersen-Perlman, J. D. and Wolf, A. T.: Getting to the first handshake: Enhancing security by initiating cooperation in transboundary river basins, J. Am. Water Resour. Assoc., 51, 16881707, 2015.

Petersen-Perlman, J. D., Veilleux, J. C., and Wolf, A. T.: International water conflict and cooperation: challenges and opportunities, Water Int., 42, 105-120, 2017.

Quesnel, K. J. and Ajami, N. K.: Changes in water consumption linked to heavy news media coverage of extreme climatic events, Sci. Adv., 3, e1700784, https://doi.org/10.1126/sciadv.1700784, 2017.

Racine, E., Waldman, S., Rosenberg, J., and Illes, J.: Contemporary neuroscience in the media, Soc. Sci. Med., 71, 725-733, 2010.

Roberts, M. E., Stewart, B. M., Tingley, D., Lucas, C., Leder-Luis, J., Gadarian, S. K., Albertson, B., and Rand, D. G.: Structural topic models for open-ended survey responses, Am. J. Polit. Sci., 58, 1064-1082, 2014.

Roobavannan, M., van Emmerik, T. H. M., Elshafei, Y., Kandasamy, J., Sanderson, M. R., Vigneswaran, S., Pande, S., and Sivapalan, M.: Norms and values in sociohydrological models, Hydrol. Earth Syst. Sci., 22, 1337-1349, https://doi.org/10.5194/hess-221337-2018, 2018.

Sunchindah, A.: The Lancang-Mekong River Basin: Reflections on cooperation mechanisms pertaining to a shared watercourse, S. Rajaratnam School of International Studies, Singapore, 9, 2013.

Turner, R. A., Fitzsimmons, C., Forster, J., Mahon, R., Peterson, A., and Stead, S. M.: Measuring good governance for complex ecosystems: perceptions of coral reef-dependent communities in the Caribbean, Global Environ. Chang., 29, 105-117, 2014.

Watson, N., Deeming, H., and Treffny, R.: Beyond Bureaucracy? Assessing Institutional Change in the Governance of Water in England, Water Altern., available at: https://www. water-alternatives.org/index.php/all-abs/61-a2-3-9 (last access: 26 March 2021), 2009. 
Weaver, D. A. and Bimber, B.: Finding news stories: a comparison of searches using LexisNexis and Google News, J. Mass Commun. Q., 85, 515-530, 2008.

Wei, J., Wei, Y., Western, A., Skinner, D., and Lyle, C.: Evolution of newspaper coverage of water issues in Australia during 18432011, Ambio, 44, 319-331, 2015.

Wei, J., Wei, Y., and Western, A.: Evolution of the societal value of water resources for economic development versus environmental sustainability in Australia from 1843 to 2011, Glob. Environ. Change, 42, 82-92, 2017.

Wei, J., Wei, Y., Tian, F., Nott, N., de Witt, C., Guo, L., and Lu, Y.: News Media Coverage of Conflict and Cooperation Dynamics of Water Events in the Lancang-Mekong River Basin Datasets, [Data set], Zenodo, https://doi.org/10.5281/zenodo.4615696, 2021a.

Wei, J., Wei, Y., Tian, F., Nott, N., de Witt, C., Guo, L., and Lu, Y.: News Media Coverage of Conflict and Cooperation Dynamics of Water Events in the Lancang-Mekong River Basin - Sentiment analysis and topic analysis code, Zenodo, https://doi.org/10.5281/zenodo.4486360, 2021b.

Wolf, A. T.: The Transboundary Freshwater Dispute Database Project, Water Int., 24, 160-163, https://doi.org/10.1080/02508069908692153, 1999.

Wolf, A. T.: Shared waters: Conflict and cooperation, Annu. Rev. Environ. Resour., 32, 241-269, 2007.
Wolf, A. T., Natharius, J. A., Danielson, J. J., Ward, B. S., and Pender, J. K.: International river basins of the world, Int. J. Water Resour. D., 15, 387-427, 1999.

Wolf, A., Yoffe, S., and Giordano, M.: International Waters: Identifying Basins at Risk, Water Policy, 5, 29-29, https://doi.org/10.2166/wp.2003.0002, 2003.

Wolf, A. T., Kramer, A., Carius, A., and Dabelko, G. D.: Managing water conflict and cooperation, in: State of the World 2005 : redefining global security, edited by: Starke, L., W. W. Norton \& Company Inc., Washington, USA, 80-95, 2005.

Yoffe, S. and Larson, K.: Chapter 2 basins at risk: Water event database methodology, Department of Geography, Oregon State, Corvallis, USA, 2001

Yoffe, S., Wolf, A. T., and Giordano, M.: Conflict and cooperation over international freshwater resources: Indicators of basins at risr 1, J. Am. Water Resour. Assoc., 39, 1109-1126, 2003.

Zawahri, N. A.: Capturing the nature of cooperation, unstable cooperation and conflict over international rivers: the story of the Indus, Yarmouk, Euphrates and Tigris rivers, Int. J. Glob. Environ. Iss., 8, 286-310, 2008.

Zeitoun, M. and Mirumachi, N.: Transboundary water interaction I: reconsidering conflict and cooperation, Int. Environ. Agreem., 8, 297-316, https://doi.org/10.1007/s10784-008-9083-5, 2008. 